\title{
Identification of potential key genes associated with glioblastoma based on the gene expression profile
}

\author{
LIJUAN BO ${ }^{1 *}, \mathrm{BO} \mathrm{WEI}^{2 *}, \mathrm{CHAOHUI} \mathrm{LI}^{2}, \mathrm{ZHANFENG} \mathrm{WANG}^{2}, \mathrm{ZHENG} \mathrm{GAO}^{3}$ and ZHUANG MIAO $^{2}$ \\ Departments of ${ }^{1}$ Infections and ${ }^{2}$ Neurosurgery, China-Japan Union Hospital of Jilin University, Changchun, \\ Jilin 130033; ${ }^{3}$ Department of Neurosurgery, First Hospital of Dandong, Dandong, Liaoning 118015, P.R. China
}

Received September 23, 2015; Accepted April 3, 2017

DOI: $10.3892 / \mathrm{ol} .2017 .6460$

\begin{abstract}
Gliomas are serious primary brain tumors. The aim of the present study was to identify potential key genes associated with the progression of gliomas. The GSE31262 gene expression profile data, which included 9 glioblastoma stem cells (GSCs) samples and 5 neural stem cell samples from adult humans, were downloaded from Gene Expression Omnibus (GEO) database. limma package was used to identify differentially expressed genes (DEGs). Based on STRING database and Pearson Correlation Coefficient (PCC), a co-expression network was constructed to comprehensively understand the interactions between DEGs, and function analysis of genes in the network was conducted. Furthermore, the DEGs that were associated with prognosis were analyzed. A total of 431 DEGs were identified, including 98 upregulated DEGs and 333 downregulated DEGs. Genes including PDZ binding kinase, topoisomerase (DNA) II $\alpha$ (TOP2A), cyclin dependent kinase $(C D K)$ 1, cell division cycle 6 and NIMA related kinase 2 had a relatively high degree in the co-expression network. A set of genes including cyclin D1, CDK1 and $C D K 2$ were significantly enriched in the cell cycle and p53 signaling pathway. Additionally, 69 DEGs were identified as genes involved in glioblastoma prognosis, such as $C D K 2$ and TOP $2 A$. The genes that had a higher degree and were associated with cell cycle and p53 signaling pathway may play pivotal roles in the progress of glioblastoma.
\end{abstract}

\section{Introduction}

Gliomas are serious primary brain tumors arising from glial cells. According to the type of cells, they are histologically

Correspondence to: Dr Zhuang Miao, Department of Neurosurgery, China-Japan Union Hospital of Jilin University, 126 Xiantai Street, Changchun, Jilin 130033, P.R. China

E-mail: miaozhanghzhh@hotmail.com

${ }^{*}$ Contributed equally

Key words: gliomas, differentially expressed genes, co-expression network, prognosis classified into astrocytomas, oligodendrogliomas and oligoastrocytomas. Gliomas are further categorized into grades I to IV, according to the World Health Organization (WHO) grading system (1). The most common form of gliomas are WHO grade IV tumors (glioblastoma and its variants), which account for $82 \%$ of cases of malignant glioma (2). Incidence rates of gliomas vary significantly with histological type, age at diagnosis, gender, ethnicity and nationality (3-7). High-grade gliomas typically recur after an average period of only 6.9 months, resulting in a median patient survival of just 12-15 months following diagnosis (8). Despite having an improved prognosis compared with increased grade glial tumors, $50-75 \%$ of patients with low-grading glioma also eventually succumb to the disease. Median survival times have been reported to range between 5 and 10 years, and estimates of 10-year survival rates range between 5 and $50 \%$ (9).

The last decade has witnessed a significant improvement in the understanding of the molecular mechanisms of glioma progress. For example, integrin inhibition leads to inactivation of the transforming growth factor (TGF)- $\beta$ pathway, which controls features of malignancy, including immunosuppression, invasiveness and stemness in human glioblastoma (10). A previous study has reported that Crk-like protein efficiently regulates cell proliferation, migration and invasion induced by the TGF- $\beta$ pathway in glioblastoma (11). Additionally, zinc finger E-box binding homeobox 1 expression is responsible for the invasion and chemoresistance of glioblastoma cells by regulating the downstream effectors roundabout, axon guidance receptor, homolog 1 (Drosophila), $\mathrm{v}-\mathrm{Myb}$ avian myeloblastosis viral oncogene homolog and O-6-methyl-guanine-DNA methyl transferase (MGMT). Furthermore, previous studies have identified that epigenetic modifications occur in gliomas (12), and hypermethylated genes in gliomas include pithelial membrane protein 3, thrombospondin 1, excitatory amino-acid transporter 2 and MGMT (13-15). Based on the microarray dataset GSE31262, Sandberg et al have identified 423 upregulated and 414 downregulated genes in glioblastoma stem cells (GSCs) using the Rank Product algorithm, comparing adult human neural stem cells (ahNSCs), and inhibition of the Wnt-signaling pathway reduces proliferation and sphere forming capacity in GSCs; additionally, they also identified a 30-gene signature which is highly overexpressed in GSCs (16). Despite this, dysregulated gene networks and pathways associated with glioma 
progression remain undetected, and the molecular mechanisms of glioma remain elusive.

To further identify the potential key gene networks and pathways implicated in gliomas, based on the microarray data GSE31262 deposited by Sandberg et al (16), the differentially expressed genes (DEGs) were identified using the linear models for microarray data (limma) package, which is a popular choice for DEGs identification using microarray and high-throughput PCR data (17). Furthermore, co-expression interactions of DEGs were analyzed and a co-expression network was constructed. Functional and pathway enrichment analyses of DEGs in the co-expression network were also performed. Additionally, drugs closely associated with DEGs in the network were identified. The present study may provide more novel information for the investigation of the molecular mechanisms underlying gliomas, which contributes to a better understanding of the pathogenesis of gliomas.

\section{Materials and methods}

Obtaining and preprocessing of $m R N A$ expression profile data. The mRNA expression profile dataset GSE31262 was downloaded from the GEO database (http://www.ncbi. nlm.nih.gov/geo/), which derived from 9 individual samples of GSCs and 5 individual samples of ahNSCs taken from the adult human brain (16). The annotation platform used here was GPL2986 ABI Human Genome Survey Microarray Version 2 (Applied Biosystems; Thermo Fisher Scientific, Inc., Waltham, MA, USA). The probe ID was first converted into a gene symbol. For probes being mapped to the same gene, the average expression value was calculated as the final expression value. Then, the data were translated into $\log _{2} \log$ arithms, and the median normalization was performed using the robust multichip averaging method (18).

DEG screening. The limma package (19) in R language (http://www.bioconductor.org/packages/release/bioc/html/limma. html) was applied to identify DEGs between GSC samples and normal NSC samples. The false discovery rate (FDR) for each gene was obtained by adjusting the raw P-value with the Benjamini Hochberg method (20). FDR $\leq 0.01$ and $\log _{2}$ fold change (FC) $\mid \geq 1$ were set as the thresholds.

Hierarchical clustering analysis of DEGs. To identify the sample-specificity of DEGs, hierarchical clustering (21) was conducted. Euclidean distance (22) was chosen as a measure of distance for DEGs between GSC samples and normal NSC samples. Pheatmap package (23) in $\mathrm{R}$ was used to visualize the result of hierarchical clustering.

Co-expression network of predicted target genes. An essential prerequisite for understanding cellular functions at the molecular-level is to correctly uncover all functional interactions among various proteins in the cells. The Search Tool for the Retrieval of Interacting Genes (STRING) database (http://string-db.org/) (24) was used to select co-expression interactions of DEGs, with a co-expression coefficient $>0.6$ as the cut-off. Based on the expression values of DEGs, the Pearson Correlation Coefficient (PCC) (25) between DEGs were calculated and only pairs with $\mid \mathrm{PCCl}>0.6$ were retained. Then, the common pairs obtained by the two aforementioned methods were retained to construct the co-expression network, which was visualized using the Cytoscape software (http://www.cytoscape.org/) (26). In the network, a node represents a protein (gene), and lines represent the interactions of the proteins. The degree of each node represents the number of nodes that interact with this node.

Functional and pathway enrichment analyses. To reveal the functions of DEGs in the co-expression network, the online biological tool Database for Annotation, Visualization and Integrated Discovery (27) was used to perform Gene Ontology (GO) (28) functional enrichment analysis in biological process (BP). Kyoto Encyclopedia of Genes and Genomes (KEGG) Orthology-based Annotation System (KOBAS) was used to identify the pathways that were significantly enriched by genes. KOBAS provides the most comprehensive set of functionalities, including input by both IDs and sequences, identifying both frequent and statistically enriched pathways, offering the choices of four statistical tests and the option of multiple testing correction (29). $\mathrm{P}<0.05$ was selected as the cut-off for the enrichment analysis.

Analysis of DEGs associated with glioblastoma prognosis. Preprocessed RNA-sequencing data and clinical data of glioblastoma were downloaded from the The Cancer Genome Atlas (TCGA) database (https://cancergenome.nih.gov/). Based on the clinical data, sample files that provided survival time and status of patients were chosen for subsequent analysis.

Cox proportional hazard model $(30,31)$ was utilized to predict the association of DEGs and patient prognosis. In the present study, each DEG was defined as a covariant, and survival time of each chosen glioblastoma sample was defined as a dependent variable. Multivariate Cox proportional hazard regression analysis was performed for all DEGs. The obtained probability value for each covariant $<0.005$ was set as the cut-off, indicating that the DEG was associated with glioblastoma prognosis. The analysis was conducted using SPSS 19.0 software (IBM Corp., Armonk, NY, USA).

Identification of small-molecule drugs based on DEGs. Web-based Gene Set Analysis Toolkit (WebGestalt) incorporates information from different public resources and provides an easy way for biologists to make sense out of gene lists (32). The current version of WebGestalt includes disease and drug-associated genes. In the present study, drugs associated with genes in the co-expression network were obtained from WebGestalt. The raw P-value for the association between drugs and genes was calculated by the hypergeometric test, and adjusted using the multiple test adjustment. An adjusted $\mathrm{P}$-value $<0.05$ was set as the cut-off.

\section{Results}

Identification of DEGs and hierarchical clustering analysis. Subsequent to preprocessing, standard DEG expression profile data was illustrated (Fig. 1). Based on the criteria of FDR $<0.05$ and $\log _{2} \mathrm{FCl} \geq 1$, a total of 431 DEGs were identified in the GSC samples, including 98 upregulated DEGs and 
A

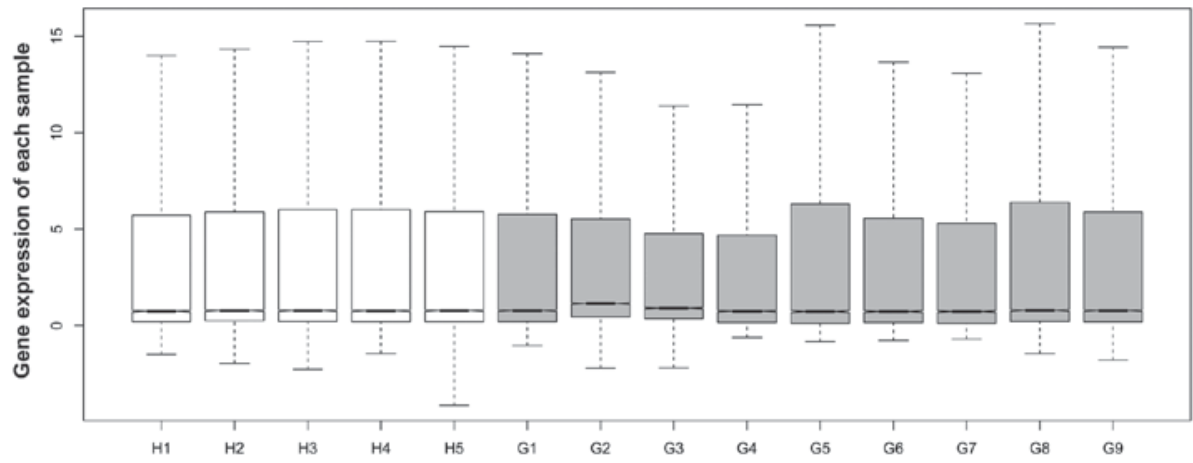

B

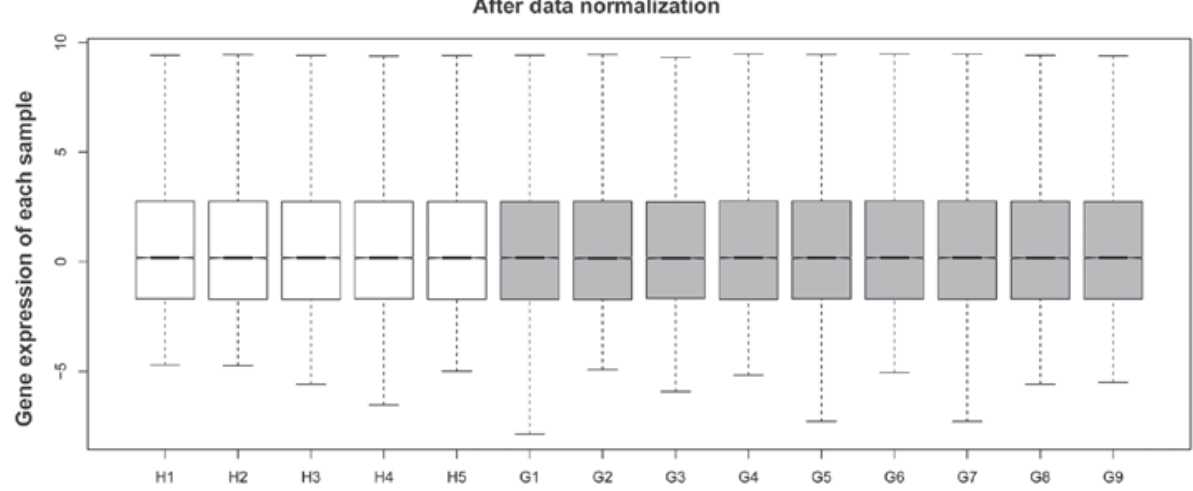

Figure 1. The boxplots for gene expression of each samples. (A) The boxplot showing gene expression of each sample prior to data normalization. (B) The boxplot showing gene expression of each sample subsequent to data normalization. The ordinate represents gene expression value, and the abscissa represents glioblastoma stem cell samples and normal controls. White columns represent normal samples, and gray columns represent glioblastoma stem cells samples. The X-axes represent the name of each sample, while the Y-axes represent the gene expression values of each sample and the horizontal lines in each column of the plot represents the mean gene expression value.

333 downregulated DEGs. Hierarchical clustering analysis illustrated that the GSCs samples and normal samples can be distinguished using the identified DEGs, according to their differential expression status (Fig. 2).

Furthermore, comparing with DEGs that identified by Sandberg et al (16), 73 upregulated DEGs and 232 downregulated DEGs were common in the present study and the study by Sandberg et al (16) (Fig. 3).

Co-expression network of the predicted target genes. To analyze the interactions of DEGs, STRING database and PCC were used to predict co-expressed interactions of DEGs. A total of 678 pairs of co-expression genes with co-expression score $>0.6$ were identified from the STRING database. In addition, 3,973 gene pairs with $\mid \mathrm{PCCl}>0.6$ were extracted. Subsequent to comparison, the 100 common gene pairs were selected. The Cytoscape software was used to visualize the co-expression network (Fig. 4), which includes a total of 33 genes and 100 interactions. Notably, all genes in this network were upregulated, and the genes PDZ binding kinase $(P B K)$, topoisomerase (DNA) II $\alpha(T O P 2 A)$, cyclin dependent kinase $(C D K) 1$, cell division cycle $(C D C) 6$ and NIMA related kinase 2 (NEK2) had a higher degree that was $>10$. $P B K, T O P 2 A$ and $C D K 1$ were co-expressed with each other.

Functional and pathway enrichment analyses of genes in the co-expression network. To further reveal the functions of DEGs in the co-expression network, the GO functional and KEGG

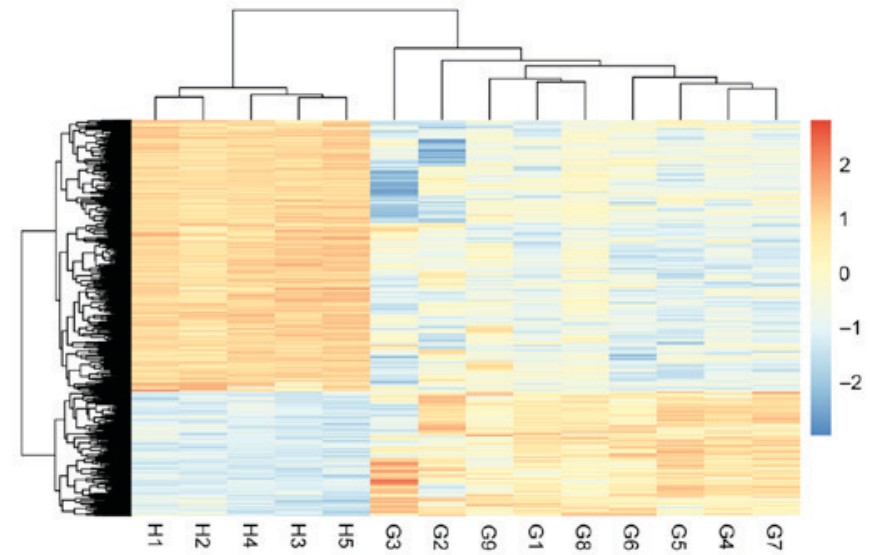

Figure 2. Hierarchical clustering analysis of differentially expressed genes. Each row represents a single gene; each column represents a sample. Red represents a high expression value; blue represents a low expression value.

pathway enrichment analyses were conducted. The majority of the GO BP terms were associated with the cell cycle, including cell cycle procession, nuclear division and chromosome segregation (Table I). Additionally, two significantly enriched pathways (cell cycle and p53 signaling pathway) were obtained (Table II). The upregulated genes involved in the cell cycle pathway included cyclin $\mathrm{B} 1(C C N B 1), C D K 1, C D C 6, C D C 45$, $D B F 4$, proliferating cell nuclear antigen, cyclin $\mathrm{A} 2$ and $C D K 2$. Genes enriched in the p53 signaling pathway were $C C N B 1$, 
A

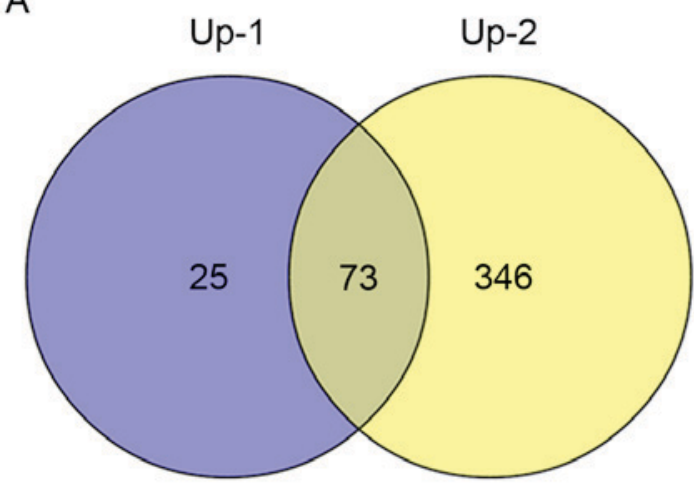

B

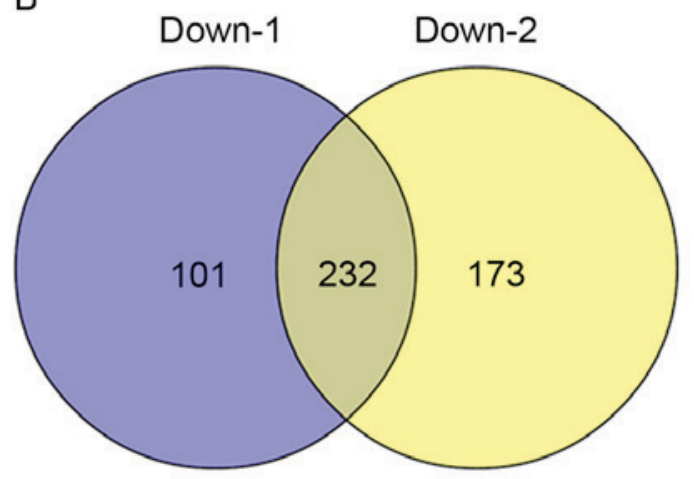

Figure 3. Venn diagrams of differentially expressed genes. (A) Venn diagram of upregulated differentially expressed genes identified in the present study and the study by Sandberg et al (16). Up-1 represents the number of upregulated genes identified in the present study, and Up-2 represents the number of upregulated genes identified the study by Sandberg et al (16). (B) Venn diagram of downregulated differentially expressed genes identified in the present study and the study by Sandberg et al (16). Down-1 represents the number of downregulated genes identified in the present study, and Down-2 represents the number of downregulated genes identified in the study of Sandberg et al (16).

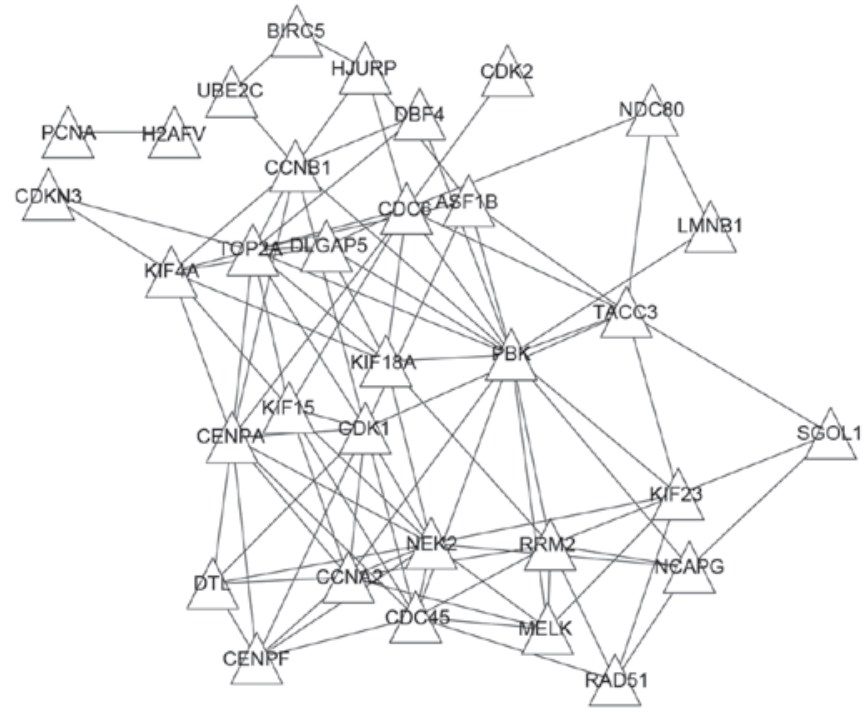

Figure 4. Co-expression network of differentially expressed genes. Triangles represent upregulated differentially expressed genes.

$C D K 1$, ribonucleotide reductase regulatory subunit $\mathrm{M} 2$ and $C D K 2$.

Screening of DEGs associated with glioblastoma prognosis. To further analyze whether the identified DEGs were associated with the prognosis of patients with glioblastoma, the survival data from the TCGA database were used in the present analysis. Among the sample files obtained from TCGA, a total of 107 files provided survival time and status of patients. Based on the Cox proportional hazard regression analysis, 69 DEGs identified in the present study were significantly associated with glioblastoma prognosis, 4 of which were present in the co-expression network, including $C D K 2$, kinesin family member 15 , kinesin family member $18 \mathrm{~A}$ and TOP $2 \mathrm{~A}$.

Identification of small-molecule drugs based on DEGs. To investigate potential drugs that may be used to treat human glioblastoma, WebGestalt was used in the present study to identify the drugs associated with the DEGs in the co-expression network. A total of 9 drugs were obtained, including paclitaxel (for genes including TOP $2 A, B I R C 5$ and $C D K 1$ ) and etoposide (for genes including TOP $2 A$ and $C D C 6$ ) (Table III).

\section{Discussion}

Malignant gliomas are the most frequently occurring primary brain tumors, and they have a poor survival rate (8). The present study aimed to investigate the potential crucial genes correlated with glioblastoma. Based on the microarray data, a total of 98 upregulated DEGs and 333 downregulated DEGs were identified from the GSCs, of which, 33 upregulated genes had co-expression interactions. In the co-expression network, genes including $P B K, T O P 2 A, C D K 1, C D C 6$ and $N E K 2$ had a higher degree. A set of genes including $C C N B 1, C D K 1, C D C 6$ and $C D K 2$ were significantly enriched in the cell cycle.

The $P B K$ gene encodes $\mathrm{PBK}$, and it has been previously suggested that mitotic phosphorylation is required for its catalytic activity $(33,34)$. The present results illustrated that $P B K$ expression is upregulated in gliomas. Multiple previous studies have shown the present results (35-37). A previous study has demonstrated that gene knockdown of $P B K$ leads to decreased viability and sphere formation of glioma initiating cells (GICs), and the PBK inhibitor HITOPK-032 abolishes growth and elicits a large increase in apoptosis of GICs, indicating an important role of $P B K$ in the cell growth of glioma (38). As a result, the present study speculated that $P B K$ may play a pivotal role in glioblastoma via the regulation of the cell cycle. The TOP $2 A$ gene encodes TOP2A which controls and alters the topologic states of DNA during transcription (39). The present results showed an upregulated expression of TOP $2 \mathrm{~A}$ protein in glioma, which has also been identified in numerous cancers (40-42). In addition to its roles in DNA synthesis and transcription, and chromosomal segregation during mitosis, Tsavaris et al (43) has reported that TOP $2 A$ is also a sensitive and specific marker of actively proliferating cells. In the present study, TOP $2 A$ was found to be significantly involved in the prognosis of patients with glioblastoma, which was consistent with numerous previous studies (44-46). NEK2 encodes a serine/threonine-protein kinase, which is involved in mitotic regulation (47). Laakso and Hautaniemi (48) has previously 
Table I. Biological processes of differentially expressed genes in the co-expression network.

\begin{tabular}{|c|c|c|c|c|}
\hline Term & Process & Count & P-value & FDR \\
\hline GO:0022403 & Cell cycle phase & 21 & $2.02 \times 10^{-23}$ & $2.79 \times 10^{-20}$ \\
\hline GO:0007049 & Cell cycle & 24 & $1.03 \times 10^{-22}$ & $1.42 \times 10^{-19}$ \\
\hline GO:0000278 & Mitotic cell cycle & 20 & $1.31 \times 10^{-22}$ & $1.80 \times 10^{-19}$ \\
\hline GO:0022402 & Cell cycle progression & 22 & $2.23 \times 10^{-22}$ & $3.08 \times 10^{-19}$ \\
\hline GO:0000279 & M phase & 19 & $8.50 \times 10^{-22}$ & $1.17 \times 10^{-18}$ \\
\hline GO:0007067 & Mitosis & 17 & $3.30 \times 10^{-21}$ & $4.56 \times 10^{-18}$ \\
\hline GO:0000280 & Nuclear division & 17 & $3.30 \times 10^{-21}$ & $4.56 \times 10^{-18}$ \\
\hline GO:0000087 & M phase of mitotic cell cycle & 17 & $4.43 \times 10^{-21}$ & $6.12 \times 10^{-18}$ \\
\hline GO:0048285 & Organelle fission & 17 & $6.35 \times 10^{-21}$ & $8.77 \times 10^{-18}$ \\
\hline GO:0007059 & Chromosome segregation & 10 & $1.13 \times 10^{-13}$ & $1.57 \times 10^{-10}$ \\
\hline GO:0051301 & Cell division & 13 & $9.02 \times 10^{-13}$ & $1.25 \times 10^{-9}$ \\
\hline GO:0051726 & Regulation of cell cycle & 13 & $3.51 \times 10^{-12}$ & $4.85 \times 10^{-9}$ \\
\hline GO:0006260 & DNA replication & 10 & $2.72 \times 10^{-10}$ & $3.75 \times 10^{-7}$ \\
\hline GO:0051276 & Chromosome organization & 11 & $7.20 \times 10^{-8}$ & $9.95 \times 10^{-5}$ \\
\hline GO:0006259 & DNA metabolism & 10 & $1.29 \times 10^{-6}$ & $1.78 \times 10^{-3}$ \\
\hline
\end{tabular}

FDR, false discovery rate.

Table II. Pathway enrichment analysis of the differentially expressed genes enriched in the co-expression network.

\begin{tabular}{lllll}
\hline ID & \multicolumn{1}{c}{ Pathway } & P-value & FDR & \multicolumn{1}{c}{ Genes } \\
\hline hsa04110 & Cell cycle & $6.96 \times 10^{-9}$ & $1.39 \times 10^{-7}$ & CCNB1, CDK1, CDC6,CDC45,DBF4,PCNA, \\
hsa04115 & p53 signaling pathway & $5.94 \times 10^{-4}$ & $5.93 \times 10^{-3}$ & $C C N A 2, C D K 2$ \\
\hline
\end{tabular}

FDR, false discovery rate.

Table III. The significant drugs associated with differentially expressed genes in co-expressed genes.

\begin{tabular}{|c|c|c|c|}
\hline Drug & ID & Parameters & Genes \\
\hline Paclitaxel & DB_ID:PA450761 & $\mathrm{O}=5 ; \operatorname{rawP}=9.99 \times 10^{-9} ; \operatorname{adj} \mathrm{P}=1.90 \times 10^{-7}$ & TOP 2A, BIRC5, CDK1, TACC 3, CENPF \\
\hline Etoposide & DB_ID:PA449552 & $\mathrm{O}=5 ; \operatorname{rawP}=4.20 \times 10^{-8} ; \operatorname{adjP}=3.99 \times 10^{-7}$ & TOP2A, CDC6, BIRC5, CDK1, DBF4 \\
\hline Hydroxyurea & DB_ID:PA449942 & $\mathrm{O}=4 ; \operatorname{rawP}=1.86 \times 10^{-7} ; \operatorname{adj} \mathrm{P}=8.83 \times 10^{-7}$ & RRM2, PCNA, CDK2, RAD51 \\
\hline Mechlorethamine & DB_ID:PA450336 & $\mathrm{O}=3 ; \operatorname{rawP}=1.85 \times 10^{-7} ; \operatorname{adj} \mathrm{P}=8.83 \times 10^{-7}$ & $C C N B 1, C D K 2, C D K 1$ \\
\hline Podofilox & DB_ID:PA450993 & $\mathrm{O}=4 ; \operatorname{rawP}=7.57 \times 10^{-7} ; \operatorname{adj} \mathrm{P}=2.88 \times 10^{-6}$ & TOP2A, CDC6, BIRC5, DBF4 \\
\hline Progesterone & DB_ID:PA451123 & $\mathrm{O}=4 ; \operatorname{rawP}=3.61 \times 10^{-6} ; \operatorname{adj} \mathrm{P}=9.80 \times 10^{-6}$ & TOP2A, CCNA2, CCNB1, RAD51 \\
\hline Cisplatin & DB_ID:PA449014 & $\mathrm{O}=4 ; \operatorname{rawP}=3.50 \times 10^{-6} ; \operatorname{adj} \mathrm{P}=9.80 \times 10^{-6}$ & TOP2A, RRM2, BIRC5, RAD51 \\
\hline Docetaxel & DB_ID:PA449383 & $\mathrm{O}=3 ; \operatorname{rawP}=4.93 \times 10^{-6} ; \operatorname{adj} \mathrm{P}=1.17 \times 10^{-5}$ & TOP $2 A, R R M 2, B I R C 5$ \\
\hline Adenosine & DB_ID:PA448049 & $\mathrm{O}=5 ; \operatorname{rawP}=2.98 \times 10^{-5} ; \operatorname{adj} \mathrm{P}=5.66 \times 10^{-5}$ & TOP2A, PCNA, CDK2, RAD51, NCAPG \\
\hline
\end{tabular}

$\mathrm{O}$, number of genes in the gene set and in the category; rawP, P-value from hypergeometric test; adjP, P-value adjusted by the multiple test adjustment.

reported that $N E K 2$ is upregulated in glioblastoma, which is consistent with the present findings. The overexpression of NEK2 has also been found in human breast and liver cancer, and colorectal carcinoma (49). Cappello et al (50) identified that NEK2 knockdown induced aneuploidy and cell cycle arrest that further led to cell death in various human breast cancer cell lines. Therefore, inhibiting the expression of the $P B K, T O P 2 A$ and $N E K 2$ genes may be a novel approach for glioma therapy.

According to the pathway enrichment analysis, the majority of significantly altered pathways were involved 
in the cell cycle, which is consistent with the BP analysis, and genes involved in this pathway included $C D K 1, C D C 6$, $D B F 4, C C N B 1$ and $C D K 2$. Cancer cells differ from normal cells by numerous important characteristics, including loss of differentiation, increased invasiveness and decreased drug sensitivity. The conversion of normal cells into cancer cells is facilitated by the loss of fidelity in cell cycle progression, which under normal conditions is achieved by the coordinated activity of CDKs, checkpoint controls and repair pathways in the cell cycle (51-53). Furthermore, numerous studies have shown that this fidelity can be abrogated by specific genetic changes (54-56). Both $C D K 1$ and $C D K 2$ encode CDKs, which are highly conserved proteins functioning as a serine/threonine kinase $(57,58)$. Overexpression of $C D K 1$ and $C D K 2$ promotes oncogenesis and progression of human gliomas, whereas downregulation of $C D K 1$ and $C D K 2$ expression inhibits the proliferation activities of human malignant gliomas $(59,60)$. Furthermore, $C D K 2$ was identified as a prognostic gene in the present study, which was consistent with the study by Zhang et al (61). Additionally, CDK2 is involved in the expression of other prognostic markers, including p27 and c-Met $(62,63)$. CDC6 encodes CDC6, which is a protein essential for the initiation of DNA replication (64). It has been demonstrated that $C D C 6$ expression is a marker of proliferative activity in brain tumors, including gliomas (65). CCNB1 encodes CCNB1, which is a regulatory protein of $\mathrm{cdk} 1 \mathrm{in}$ mitosis (66). An abnormally high expression level of CCNBI has been reported to be correlated with high grades and advanced stages of gliomas $(67,68)$. Collectively, genes such as $C D K 1, C D K 2, C D C 6$ and $C C N B 1$ may exert critical roles in the progress of glioblastoma through mediating cell cycle.

In the present study, $C D K 1, C D K 2$ and $C C N B 1$ were also markedly enriched in the p53 signaling pathway. P53 signaling pathway is the most commonly mutated pathway in tumorigenesis (69). As a well-known tumor suppressor, p53 responds to DNA damage and various genotoxic and cytotoxic stresses by inducing cell cycle arrest and apoptosis (70). Overall, the p53 pathway is disrupted in $\sim 80 \%$ of high-grade gliomas (WHO Grades III and IV) (71). Therefore, in the progress of glioblastoma, $C D K 1, C D K 2$ and $C C N B 1$ may also regulate the p53 signaling pathway.

Additionally, the present study used the limma package to identify DEGs, comparing the method (Rank Product algorithm) used by Sandberg et al (16). Among the identified DEGs in the present study, 73 upregulated genes and 232 downregulated DEGs were common with those screened by Sandberg et al (16), indicating the potentially significant roles of these common DEGs in glioblastoma. However, another 25 upregulated and 101 downregulated DEGs, which were not found by Sandberg et al (16), were also screened. The results suggest that it is necessary to reanalyze the public microarray data using different methods. The roles of these DEGs identified in the present study in glioblastoma require additional investigation. Additionally, the expression levels and functions of the genes associated with the cell cycle and the p53 signaling pathway in glioblastoma require validation by experiments, which will be conducted and reported later.

In conclusion, a total of 98 upregulated DEGs and 333 downregulated DEGs were identified from the GSCs compared with the ahNSCs. The upregulated hub genes in the co-expression network (including $P B K, T O P 2 A, C D K 1, C D C 6$ and $N E K 2$ ) and the DEGs (including $C C N B 1, C D K 1, C D C 6$, and $C D K 2$ ) that correlated with cell cycle and the p53 signaling pathway may have essential roles in the progress of glioblastoma. These genes may be potentially therapeutic targets of gliomas, and the findings may be helpful to identify the molecular mechanisms of the pathogenesis of glioblastoma.

\section{References}

1. Lassman AB: Molecular biology of gliomas. Curr Neurol Neurosci Rep 4: 228-233, 2004.

2. Dolecek TA, Propp JM, Stroup NE and Kruchko C: CBTRUS statistical report: Primary brain and central nervous system tumors diagnosed in the United States in 2005-2009. Neuro Oncol 14 (Suppl 5): v1-v49, 2012.

3. Ostrom QT, Bauchet L, Davis FG, Deltour I, Fisher JL, Langer CE, Pekmezci M, Schwartzbaum JA, Turner MC, Walsh KM, et al: The epidemiology of glioma in adults: A 'state of the science' review. Neuro Oncol 16: 896-913, 2014.

4. Ostrom QT, Gittleman H, Farah P, Ondracek A, Chen Y, Wolinsky Y, Stroup NE, Kruchko C and Barnholtz-Sloan JS: CBTRUS statistical report: Primary brain and central nervous system tumors diagnosed in the United States in 2006-2010. Neuro Oncol 15 (Suppl 2): ii1-ii56, 2013.

5. Lee CH, Jung KW, Yoo H, Park S and Lee SH: Epidemiology of primary brain and central nervous system tumors in Korea. J Korean Neurosurg Soc 48: 145-152, 2010.

6. Gigineishvili D, Shengelia N, Shalashvili G, Rohrmann S, Tsiskaridze A and Shakarishvili R: Primary brain tumour epidemiology in Georgia: First-year results of a population-based study. J Neurooncol 112: 241-246, 2013.

7. Dubrow R and Darefsky AS: Demographic variation in incidence of adult glioma by subtype, United States, 1992-2007. BMC Cancer 11: 325, 2011.

8. Watkins S and Sontheimer H: Unique biology of gliomas: Challenges and opportunities. Trends Neurosci 35: 546-556, 2012.

9. Sanai N and Berger MS: Recent surgical management of gliomas. In: Glioma. Yamanaka R (ed). Vol 746. Springer, New York, pp12-25, 2012.

10. Roth P, Silginer M, Goodman SL, Hasenbach K, Thies S, Maurer G, Schraml P, Tabatabai G, Moch H, Tritschler I and Weller M: Integrin control of the transforming growth factor- $\beta$ pathway in glioblastoma. Brain 136: 564-576, 2013.

11. Lv S, Qin J, Yi R, Coreman M, Shi R, Kang H and Yao C: CrkL efficiently mediates cell proliferation, migration, and invasion induced by TGF- $\beta$ pathway in glioblastoma. J Mol Neurosci 51: 1046-1051, 2013.

12. Feinberg AP and Tycko B: The history of cancer epigenetics. Nat Rev Cancer 4: 143-153, 2004.

13. Hegi ME, Diserens AC, Gorlia T, Hamou MF, de Tribolet N, Weller M, Kros JM, Hainfellner JA, Mason W, Mariani L, et al: MGMT gene silencing and benefit from temozolomide in glioblastoma. N Engl J Med 352: 997-1003, 2005.

14. Kunitz A, Wolter M, Van Den Boom J, Felsberg J, Tews B, Hahn M, Benner A, Sabel M, Lichter P, Reifenberger G, et al: DNA hypermethylation and aberrant expression of the EMP3 gene at 19q13. 3 in human gliomas. Brain Pathol 17: 363-370, 2007.

15. Zschocke J, Allritz C, Engele J and Rein T: DNA methylation dependent silencing of the human glutamate transporter EAAT2 gene in glial cells. Glia 55: 663-674, 2007.

16. Sandberg CJ, Altschuler G, Jeong J, Strømme KK, Stangeland B, Murrell W, Grasmo-Wendler UH, Myklebost O, Helseth E, Vik-Mo EO, et al: Comparison of glioma stem cells to neural stem cells from the adult human brain identifies dysregulated Wnt-signaling and a fingerprint associated with clinical outcome. Exp Cell Res 319: 2230-2243, 2013.

17. Ritchie ME, Phipson B, Wu D, Hu Y, Law CW, Shi W and Smyth GK: Limma powers differential expression analyses for RNA-sequencing and microarray studies. Nucleic Acids Res 43: e47, 2015 .

18. Irizarry RA, Hobbs B, Collin F, Beazer-Barclay YD, Antonellis KJ, Scherf U and Speed TP: Exploration, normalization, and summaries of high density oligonucleotide array probe level data. Biostatistics 4: 249-264, 2003 
19. Smyth G: Limma: Linear models for microarray data. In: Bioinformatics and computational biology solutions using $\mathrm{R}$ and Bioconductor. Gentleman R, Carey V, Dudoit S, Irizarry R and Huber W (eds). Springer, New York, pp397-420, 2005.

20. Benjamini Y and Hochberg Y: Controlling the false discovery rate: A practical and powerful approach to multiple testing. J Royal Statistic Soci. Series B (Methodological) 57: 289-300, 1995 .

21. Szekely GJ and Rizzo ML: Hierarchical clustering via joint between-within distances: Extending Ward's minimum variance method. Journal of Classification 22: 151-183, 2005.

22. Deza MM and Deza E: Encyclopedia of distances. Springer, 2009.

23. Wang L, Cao C, Ma Q, Zeng Q, Wang H, Cheng Z, Zhu G, Qi J, $\mathrm{Ma} \mathrm{H}$, Nian $\mathrm{H}$ and Wang Y: RNA-seq analyses of multiple meristems of soybean: Novel and alternative transcripts, evolutionary and functional implications. BMC Plant Biol 14: 169, 2014.

24. Szklarczyk D, Franceschini A, Kuhn M, Simonovic M, Roth A, Minguez P, Doerks T, Stark M, Muller J, Bork P, et al: The STRING database in 2011: Functional interaction networks of proteins, globally integrated and scored. Nucleic Acids Res 39 (Database Issue): D561-D568, 2011.

25. Obayashi T, Kinoshita K, Nakai K, Shibaoka M, Hayashi S, Saeki M, Shibata D, Saito K and Ohta H: ATTED-II: A database of co-expressed genes and cis elements for identifying co-regulated gene groups in Arabidopsis. Nucleic Acids Res 35 (Database Issue): D863-D869, 2007.

26. Smoot ME, Ono K, Ruscheinski J, Wang PL and Ideker T: Cytoscape 2.8: New features for data integration and network visualization. Bioinformatics 27: 431-432, 2011.

27. Huang DW, Sherman BT and Lempicki RA: Bioinformatics enrichment tools: Paths toward the comprehensive functional analysis of large gene lists. Nucleic Acids Res 37: 1-13, 2009.

28. Ashburner M, Ball CA, Blake JA, Botstein D, Butler H, Cherry JM, Davis AP, Dolinski K, Dwight SS, Eppig JT, et al: Gene ontology: Tool for the unification of biology. The gene ontology consortium. Nat Genet 25: 25-29, 2000.

29. Mao X, Cai T, Olyarchuk JG and Wei L: Automated genome annotation and pathway identification using the KEGG Orthology $(\mathrm{KO})$ as a controlled vocabulary. Bioinformatics 21 3787-3793, 2005.

30. Motakis E, Ivshina AV and Kuznetsov VA: Data-driven approach to predict survival of cancer patients: Estimation of microarray genes' prediction significance by Cox proportional hazard regression model. IEEE Eng Med Biol Mag 28: 58-66, 2009.

31. Liu W, Hao XS, Fan Q, Li HX, Song LN, Wang SJ, Wang PZ, Jin Y, Chen Y, Guan LY, et al: Cox proportional hazard mode analysis of prognosis in patients with carcinoma of esophagus and gastric cardia after radical resection. Zhonghua Zhong Liu Za Zhi 30: 921-925, 2008 (In Chinese).

32. Zhang B, Kirov S and Snoddy J: WebGestalt: An integrated system for exploring gene sets in various biological contexts. Nucleic Acids Res 33 (Web Server Issue): W741-W748, 2005.

33. Park JH, Jeong YJ, Won HK, Choi SY, Park JH and Oh SM: Activation of TOPK by lipopolysaccharide promotes induction of inducible nitric oxide synthase through NF- $\kappa \mathrm{B}$ activity in leukemia cells. Cell Signal 26: 849-856, 2014.

34. Park JH, Lin ML, Nishidate T, Nakamura Y and Katagiri T: PDZ-binding kinase/T-LAK cell-originated protein kinase, a putative cancer/testis antigen with an oncogenic activity in breast cancer. Cancer Res 66: 9186-9195, 2006.

35. Stangeland B, Mughal AA, Grieg Z, Sandberg CJ, Joel M, Nygard S, Meling T, Murrell W, Vik Mo EO and Langmoen IA Combined expressional analysis, bioinformatics and targeted proteomics identify new potential therapeutic targets in glioblastoma stem cells. Oncotarget 6: 26192-26215, 2015.

36. Wei B, Wang L, Du C, Hu G, Wang L, Jin Y and Kong D Identification of differentially expressed genes regulated by transcription factors in glioblastomas by bioinformatics analysis. Mol Med Rep 11: 2548-2554, 2015.

37. Freitas M, Malheiros S, Stávale JN, Biassi TP, Zamunér FT, de Souza Begnami M, Soares FA and Vettore AL: Expression of cancer/testis antigens is correlated with improved survival in glioblastoma. Oncotarget 4: 636, 2013.

38. Joel M, Mughal AA, Grieg Z, Murrell W, Palmero S, Mikkelsen B, Fjerdingstad HB, Sandberg CJ, Behnan J, Glover JC, et al Targeting PBK/TOPK decreases growth and survival of glioma initiating cells in vitro and attenuates tumor growth in vivo. Mol Cancer 14: 121, 2015
39. Escargueil AE, Plisov SY, Filhol O, Cochet $\mathrm{C}$ and Larsen AK: Mitotic phosphorylation of DNA topoisomerase II alpha by protein kinase CK 2 creates the MPM-2 phosphoepitope on Ser-1469. J Biol Chem 275: 34710-34718, 2000

40. Fasching PA, Weihbrecht S, Haeberle L, Gasparyan A, Villalobos IE, Ma Y, Ekici AB, Wachter DL, Hartmann A, Beckmann MW, et al: HER2 and TOP2A amplification in a hospital-based cohort of breast cancer patients: Associations with patient and tumor characteristics. Breast Cancer Res Treat 145: 193-203, 2014.

41. Jain M, Zhang L, He M, Zhang YQ, Nilubol N, Shen M and Kebebew E: TOP2A is a therapeutic target for adrenocortical carcinoma. Cancer Res 73: 3543, 2013

42. Kirk J, Schaarschuch K, Dalimov Z, Lasorsa E, Ku S, Ramakrishnan S, Hu Q, Azabdaftari G, Wang J, Pili R and Ellis L: Top2a identifies and provides epigenetic rationale for novel combination therapeutic strategies for aggressive prostate cancer. Oncotarget 6: 3136-3146, 2015.

43. Tsavaris N, Lazaris A, Kosmas C, Gouveris P, Kavantzas N, Kopterides P, Papathomas T, Arapogiannis G, Zorzos H, Kyriakou V and Patsouris E: Topoisomerase I and IIalpha protein expression in primary colorectal cancer and recurrences following 5-fluorouracil-based adjuvant chemotherapy. Cancer Chemother Pharmacol 64: 391-398, 2009

44. Arivazhagan A, Kumar DM, Sagar V, Patric IR, Sridevi S, Thota B, Srividya MR, Prasanna K, Thennarasu K, Mondal N, et al: Higher topoisomerase 2 alpha gene transcript levels predict better prognosis in GBM patients receiving temozolomide chemotherapy: Identification of temozolomide as a TOP2A inhibitor. J Neurooncol 107: 289-297, 2012.

45. Bie L, Zhao G, Cheng P, Rondeau G, Porwollik S, Ju Y, Xia XQ and McClelland M: The accuracy of survival time prediction for patients with glioma is improved by measuring mitotic spindle checkpoint gene expression. PLoS One 6: e25631, 2011.

46. Zhang X, Yang H, Gong B, Jiang C and Yang L: Combined gene expression and protein interaction analysis of dynamic modularity in glioma prognosis. J Neurooncol 107: 281-288, 2012.

47. Schultz SJ, Fry AM, Sütterlin C, Ried T and Nigg EA: Cell cycle-dependent expression of Nek2, a novel human protein kinase related to the NIMA mitotic regulator of Aspergillus nidulans. Cell Growth Differ 5: 625-635, 1994.

48. Laakso M and Hautaniemi S: DEGs in Glioblastoma, 2011. http:// csbi.ltdk.helsinki.fi/camda/candidateReport-document.pdf. Accessed February 2, 2015.

49. Chen YJ, Lin HS and Jiang JK: Overexpression of nek 2 in colorectal carcinoma. Cancer Research 68: 5509, 2008.

50. Cappello P, Blaser H, Gorrini C, Lin D, Elia A, Wakeham A, Haider S, Boutros P, Mason J, Miller NA, et al: Role of Nek2 on centrosome duplication and aneuploidy in breast cancer cells. Oncogene 33: 2375-2384, 2014.

51. Evan GI and Vousden KH: Proliferation, cell cycle and apoptosis in cancer. Nature 411: 342-348, 2001.

52. Kastan MB and Bartek J: Cell-cycle checkpoints and cancer. Nature 432: 316-323, 2004

53. Vermeulen K, Van Bockstaele DR and Berneman ZN: The cell cycle: A review of regulation, deregulation and therapeutic targets in cancer. Cell Prolif 36: 131-149, 2003.

54. Tang S, Bonaroti J, Unlu S, Liang X, Tang D, Zeh HJ and Lotze MT: Sweating the small stuff: microRNAs and genetic changes define pancreatic cancer. Pancreas 42: 740-759, 2013.

55. Gollin SM, Parikh RA and Huang X: Genetic changes in ATM and ATR/CHEK1 as prognostic indicators in cancer. US Patent 20130338212 A1. Filed June 10, 2013; issued December 19, 2013.

56. Cairns RA, Harris IS and Mak TW: Regulation of cancer cell metabolism. Nat Rev Cancer 11: 85-95, 2011.

57. Fourest-Lieuvin A, Peris L, Gache V, Garcia-Saez I, JuillanBinard C, Lantez V and Job D: Microtubule regulation in mitosis: Tubulin phosphorylation by the cyclin-dependent kinase Cdk1. Mol Biol Cell 17: 1041-1050, 2006.

58. Gu Y, Rosenblatt J and Morgan DO: Cell cycle regulation of CDK2 activity by phosphorylation of Thr160 and Tyr15. Embo J 11: 3995-4005, 1992

59. Chen H, Huang Q, Zhai DZ, Dong J, Wang AD and Lan Q: CDK1 expression and effects of CDK1 silencing on the malignant phenotype of glioma cells. Zhonghua Zhong Liu Za Zhi 29: 484-488, 2007.

60. Zhang R, Banik NL and Ray SK: Combination of all-trans retinoic acid and interferon-gamma upregulated p27(kip1) and down regulated CDK2 to cause cell cycle arrest leading to differentiation and apoptosis in human glioblastoma LN18 (PTEN-proficient) and U87MG (PTEN-deficient) cells. Cancer Chemother Pharmacol 62: 407-416, 2008. 
61. Zhang J, Liu B, Jiang X, Zhao H, Fan M, Fan Z, Lee JJ, Jiang T, Jiang T and Song SW: A systems biology-based gene expression classifier of glioblastoma predicts survival with solid tumors. PLoS One 4: e6274, 2009.

62. Kong DS, Song SY, Kim DH, Joo KM, Yoo JS, Koh JS, Dong SM, Suh YL, Lee JI, Park K, et al: Prognostic significance of c-Met expression in glioblastomas. Cancer 115: 140-148, 2009.

63. Kirla RM, Haapasalo HK, Kalimo H and Salminen EK: Low expression of p27 indicates a poor prognosis in patients with high-grade astrocytomas. Cancer 97: 644-648, 2003.

64. Saha P, Chen J, Thome KC, Lawlis SJ, Hou ZH, Hendricks M, Parvin JD and Dutta A: Human CDC6/Cdc18 associates with Orc1 and cyclin-cdk and is selectively eliminated from the nucleus at the onset of S phase. Mol Cell Biol 18: 2758-2767, 1998.

65. Ohta S, Koide M, Tokuyama T, Yokota N, Nishizawa S and Namba H: Cdc6 expression as a marker of proliferative activity in brain tumors. Oncol Rep 8: 1063-1066, 2001.

66. Petri ET, Errico A, Escobedo L, Hunt T and Basavappa R: The crystal structure of human cyclin B. Cell Cycle 6: 1342-1349, 2007.
67. Zhang J, Zhao P, Fu Z, Chen X, Liu N, Lu A, Li R, Shi L, Pu P, Kang $C$ and You Y: Glioma cells enhance endothelial progenitor cell angiogenesis via VEGFR-2, not VEGFR-1. Oncol Rep 20: 1457-1463, 2008

68. Ducray F, Idbaih A, de Reyniès A, Bièche I, Thillet J, Mokhtari K, Lair S, Marie Y, Paris S, Vidaud M, et al: Anaplastic oligodendrogliomas with $1 \mathrm{p} 19 \mathrm{q}$ codeletion have a proneural gene expression profile. Mol Cancer 7: 41, 2008.

69. Bode AM and Dong Z: Post-translational modification of p53 in tumorigenesis. Nat Rev Cancer 4: 793-805, 2004.

70. Tanaka H, Arakawa H, Yamaguchi T, Shiraishi K, Fukuda S, Matsui K, Takei Y and Nakamura Y: A ribonucleotide reductase gene involved in a p53-dependent cell-cycle checkpoint for DNA damage. Nature 404: 42-49, 2000.

71. Mao H, LeBrun DG, Yang J, Zhu VF and Li M: Deregulated signaling pathways in glioblastoma multiforme: Molecular mechanisms and therapeutic targets. Cancer Invest 30: 48-56, 2012. 